\title{
CONTAMINATION OF ANTI-VEGF DRUGS FOR INTRAVITREAL INJECTION
}

\section{How Do Repackaging and Newly Developed Syringes Affect the Amount of Silicone Oil Droplets and Protein Aggregates?}

\author{
MARC SCHARGUS, MD, $* \dagger$ BENJAMIN P. WERNER, MSc, \\ GERHARD WINTER, PHD
}

\begin{abstract}
Purpose: The particle counts and the nature of particles of three different antivascular endothelial growth factor agents (VEGF) in different containers in a laboratory setting were compared.

Methods: Original prefilled ranibizumab glass syringes, original vials with aflibercept, and repacked ready-to-use plastic syringes with bevacizumab from a compounding pharmacy and a compounding company (CC) were analyzed. Particle counts and size distributions were quantified by different particle characterization methods (nephelometry, light obscuration, Micro-Flow Imaging, nanotracking analysis, resonant mass measurement). Using high-performance size-exclusion chromatography (HP-SEC), levels of protein drug monomer and soluble aggregates were determined.

Results: Nearly all samples showed similar product quality. Light obscuration and MicroFlow Imaging showed a 4-fold to 9-fold higher total particle count in compounding company bevacizumab (other samples up to 42,000 particles $/ \mathrm{mL}$ ). Nanotracking analysis revealed highest values for compounding company bevacizumab (6,375 million particles/ $\mathrm{mL}$ ). All containers showed similar amounts of silicone oil microdroplets. Ranibizumab showed lowest particle count of all tested agents with only one monomer peak in HP-SEC. Repackaged bevacizumab from different suppliers showed varying product quality.

Conclusion: All three tested agents are available in similar quality regarding particulate purity and silicone oil microdroplet count. Repackaging can have a major impact on the quality.

RETINA 38:2088-2095, 2018
\end{abstract}

I

ntravitreal antivascular endothelial growth factor (VEGF) agents, including ranibizumab (Lucentis; Genentech, San Francisco, CA), bevacizumab (Avastin; Genentech) and aflibercept (Eylea; Regeneron

From the *Department of Ophthalmology, Heinrich Heine University Düsseldorf, Düsseldorf, Germany; †Eye Hospital Schweinfurt-Gerolzhofen, Gerolzhofen, Germany; and $\$$ Department of Pharmacy, Pharmaceutical Technology and Biopharmaceutics, Ludwig-Maximilians-University, Munich, Germany.

None of the authors has any financial/conflicting interests to disclose.

Owing to the limited number of samples and the need to dilute 20 fold for analysis, the statistical value of the data is limited.

M. Schargus and B.P. Werner contributed equally to this work.

Reprint requests: Marc Schargus, MD, MHBA, FEBO, Department of Ophthalmology, Heinrich-Heine-University Düsseldorf, Moorenstraße 5, 40225 Düsseldorf, Germany; e-mail: marc.schargus@gmx.de
Pharmaceuticals, Inc, Tarrytown, NY), are used for years to treat several kinds of retinal vascular disorders. ${ }^{1-3}$ Short-term and transient intraocular pressure (IOP) rise is well known to occur after intravitreal injection and is easy to explain because of injection of the fluid volume into the vitreous with the different anti-VEGF agents. ${ }^{4,5}$ Long-term or sustained IOP rise has a more difficult mechanism and has been reported clinically in several case reports and case series. Bakri et $\mathrm{al}^{6}$ first reported sustained IOP rise after ranibizumab injections requiring medical treatment in a small series of four patients and Kahook et al reported similar findings in six patients. ${ }^{7}$ Several studies with different number of patients followed reporting prevalence of long-term IOP rise after treatment with ranibizumab, bevacizumab, or aflibercept injections. ${ }^{7-20}$ 
Recent retrospective analysis of the VIEW 1 and 2 data of 2,457 patients showed significant higher IOP elevation in ranibizumab than in aflibercept injected eyes. ${ }^{21}$ This study showed for the first time in a high number of patients a statistically significant IOP elevation difference between these two agents. Notably all studies evaluating IOP elevations after anti-VEGF injections are limited because of the retrospective design of the analysis.

Several mechanisms have been proposed to explain clinically significant IOP elevation after anti-VEGF treatment. Such mechanisms include mechanical trauma to the trabecular meshwork from repeated injection-related IOP spikes and a decrease in aqueous outflow because of VEGF blockade, as potentially mediated by inhibition of nitric oxide synthesis, or inflammation or obstruction by high molecular weight protein aggregates or silicone microdroplets. $22-24$ Because of the different size of molecules (bevacizumab has a molecular weight of $149 \mathrm{kDa}$, aflibercept of $115 \mathrm{kDa}$, and ranibizumab of $48 \mathrm{kDa}$ ), it has been assumed that the agents can accumulate in the trabecular meshwork especially after long-term repeated administration and cause either direct obstruction or indirect change of the outflow facility. Other proposed mechanisms postulate outflow obstruction by protein aggregates and/or silicone oil droplets from the syringes or needles used. ${ }^{24-26}$ Liu et al reported both protein aggregates and particles $\geq 1 \mu \mathrm{m}$ in repackaged bevacizumab obtained from three external compounding pharmacies in the United States. ${ }^{26}$

All three agents are currently prepared and distributed in different containers. Ranibizumab comes in two possible injection containers. First, there is a single-dose vial, which is drawn into a syringe immediately before injection. Second, since 2013, there is a prefilled syringe available in the European Union, which has been approved also by the U.S. Food and Drug Administration (FDA) in 2016. Currently, mainly the prefilled syringe is used in central Europe. ${ }^{27,28}$ Aflibercept is only delivered in a single-dose vial, which is drawn into a syringe immediately before injection. The use of bevacizumab as intravitreal agent is off-label. Bevacizumab is therefore only available from compounding pharmacies as an agent drawn from a larger vial and then usually filled into multiple syringes, which are stored in a refrigerator at $2^{\circ} \mathrm{C}$ to $8^{\circ} \mathrm{C}$ before use. ${ }^{26}$ Theoretically, this compounding, refilling, inadvertent freeze and thaw processes carries an increased risk for aggregate and particle generation.

Liu et al quantified levels of subvisible particles and protein aggregates in repackaged bevacizumab syringes obtained from compounding pharmacies, as well as in samples of bevacizumab and ranibizumab vials tested in controlled laboratory experiments. ${ }^{25}$ The ready-to-use prefilled ranibizumab was not available at the time of Liu's publication.

Aim of this study was to add further laboratory data on levels of subvisible particles and protein aggregates in a new prefilled ranibizumab syringe product and in the aflibercept product and to compare it to samples of bevacizumab delivered from a compounding pharmacy and from a compounding company.

\section{Materials and Methods}

\section{Materials}

The products of interest were bevacizumab $25 \mathrm{mg} / \mathrm{mL}$, repackaged by the central pharmacy of the University Hospital Duesseldorf in $1 \mathrm{~mL}$ Braun syringes with a volume of $150 \mu \mathrm{L}$ (8 units; Avastin Roche $3.75 \mathrm{mg}$; batch No. B8008H10) (bevacizumab D), bevacizumab $25 \mathrm{mg} / \mathrm{mL}$, repackaged by BA.Herstellung $\mathrm{GmbH} \&$ Co. KG in a Braun micro-fine insulin syringe U100 with a 30G staked-in needle with a volume of $50 \mu \mathrm{L}$ (16 units; Avastin Roche $3.75 \mathrm{mg}$; batch No. 060117APO) (bevacizumab F), original aflibercept $40 \mathrm{mg} / \mathrm{mL}$ supplied in a vial and with a $5-\mu \mathrm{m}$ filter needle (6 units; EYLEA $40 \mathrm{mg} / \mathrm{mL}$ injection solution in a vial, Bayer; batch No. 54269C) and original ranibizumab $10 \mathrm{mg} / \mathrm{mL}$ in a siliconized glass syringe (6 units; Lucentis $10 \mathrm{mg} / \mathrm{mL}$ injection solution in a prefilled syringe; Novartis; batch No. S2050C). All units were packed in shock absorbing containers with cooling packs until arrival at the laboratory of the Department of Pharmacy, Pharmaceutical Technology and Biopharmaceutics at the Ludwig-MaximiliansUniversity in Munich. Upon arrival, all products were visually inspected for any damages. No damages and no signs of freezing were detected. Samples were stored light protected at $6^{\circ} \mathrm{C}$ in the middle of a refrigerator to prevent any impact of light or freeze-thawing effects until direct analysis.

\section{Sample Preparation}

All steps like extracting the protein solution from the product container, sample dilution, or aliquoting was carried out under a laminar flow hood according to aseptic handling. For the simulation of a real application, all products were prepared according to the manufacturer instructions. An exception of this was that the whole syringe content was used instead of disposing some of the protein solution as instructed to avoid wasting product volume, which was required for analysis. Briefly, aflibercept solution was aspirated 
from the vial with the enclosed $18 \mathrm{G} \times 1 \frac{1}{2} \mathrm{BD}$ Blunt Fill Needle - Filter (Becton, Dickinson and Company Limited, Franklin Lakes, NJ) into a BD 1-mL syringe with Luer-Lok Tip (Becton, Dickinson and Company Limited). The filter needle was removed. The following procedure was now the same as for the other two products, bevacizumab D and ranibizumab. A $30 \mathrm{G} 12^{\prime \prime}$ BD Microlance 3 (Becton, Dickinson and Company Limited, Drogheda, Ireland) was attached to the syringe and the protein solution was expelled into a 50-mL Greiner tube. The repackaged bevacizumab $\mathrm{F}$ was stored in Braun micro-fine insulin syringes U100 with a staked-in needle. In this case, the product was directly expelled into the tube. All aliquots of the same product were pooled in one tube. For analysis, the pooled samples were diluted 1:20 in the appropriate formulation buffer. The buffers were filtered before with a medical polyethersulfone filter with a pore size of $0.2 \mu \mathrm{m}$ (Pall PharmAssure; Pall GmBH, Dreieich, Germany) before the addition of the concentrated protein solution. The samples were analyzed within three days after dilution. The presented data show the calculated results for nondiluted samples except for nephelometry where the results of the diluted samples are presented. Particle analysis was performed on calibrated equipment. Duke Standards and CountCal Particle Size Standards were used (both Thermo Scientific, Fremont, CA).

\section{Methods}

Nephelometry. A Nephla turbidimeter (Dr. Lange, Düsseldorf, Germany) was used to determine the turbidity of the samples. At an angle of $90^{\circ}$, scattered light from a laser with a wavelength of $860 \mathrm{~nm}$ is detected. Triplicate measurements were performed and presented in the form of formazin nephelometric units (FNU).

Light obscuration. Light obscuration was performed by using a SVSS-C device from PAMAS GmbH and the software PAMAS PMA Program V 2.1.2.0 (Rutesheim, Germany) for the quantification of particles in the subparticle and visible particle range. The system cleanliness was tested before each sample by measuring the particle content of highly purified water. Each sample run was carried out in triplicates of $0.3 \mathrm{~mL}$ after a prerun of $0.4 \mathrm{~mL}$. Each sample was analyzed in triplicates resulting in a total of nine single runs. The speed for the aspiration of the solution was set to $10 \mathrm{~mL} /$ minute.

High-performance size-exclusion chromatography. For the evaluation of the relative amount of soluble protein species, size exclusion chromatography (HP-SEC) was carried out. A flow of $0.5 \mathrm{~mL} /$ minute with a mobile phase consisting of $300 \mathrm{mM}$ sodium chloride and $50 \mathrm{mM}$ phosphate $\mathrm{pH} 7$ in highly purified water was applied on a TSKgel 3000SWXL column (Tosoh Bioscience GmbH, Stuttgart, Germany). Samples were centrifuged before analysis for 10 minutes at $14,000 \mathrm{rpm}$. Twenty-five microliters of the diluted protein solution were injected. Each product was run six times. Analysis was carried out on a Waters 2695 Alliance Separation Module (Waters Corporation, Milford, MA) with a Waters 2487 Dual $\lambda$ Absorbance Detector for UV absorbance at $280 \mathrm{~nm}$. Data analysis was carried out with Chromeleon V6.8.

Micro-Flow Imaging. A Micro-Flow Imaging DPA 4100 device (BrightWELL Technologies Inc, Ottawa, Canada) with a $100-\mu \mathrm{m}$ flow cell in the operation mode high magnification was used. The software MFI Particle Analyzer V6.9.7.2 was applied for analysis. The flow cell was flushed with highly purified water and flow cell cleanliness was checked between each run. The cell was flushed with $0.5 \mathrm{~mL}$ of the corresponding buffer to optimize illumination, which ensures a correct system thresholding, before each analysis. Next, the cell was loaded with $0.3 \mathrm{~mL}$ before $0.65 \mathrm{~mL}$ of the sample was analyzed at a flow rate of $0.1 \mathrm{~mL} /$ minute. Triplicate measurements were performed.

Nanotracking analysis. A NanoSight LM20 (NanoSight, Amesbury, United Kingdom) with the software NTA 2.3 was used for capturing the particle movement in the nanometer range for 60 seconds. The camera shutter and gain were set to 1,497 and 680, respectively. The sample cell was flushed with highly purified water before it was loaded air bubble free with $0.5 \mathrm{~mL}$ sample. Between each analysis of the triplicate, $0.1 \mathrm{~mL}$ sample was loaded into the cell. Loading was performed with a 1-mL Terumo Syringe without needle (Terumo (Philippines) Corporation, Laguna, Philippines). During video capture, no flow was applied.

Resonant mass measurement. For the differentiation of protein and silicone oil particles in a particle size range from $300 \mathrm{~nm}$ to $5 \mu \mathrm{m}$, resonant mass measurement with a Hi-Q Micro Sensor was carried out (Affinity Biosensors LLC, Santa Barbara, CA). Before the sample was loaded for 40 seconds, the sensor was flushed with highly purified water. Next, in the automatic limit of detection mode, the limit of detection was determined three times before calculating the mean value. The mean value was then used for the measurement. Analysis was stopped either after the volume reached $150 \mathrm{~nL}$ or 10 minutes. The manual stop needed to be performed because of very low particle counts in the samples leading to a wrongly recognized analysis volume. The density of protein 


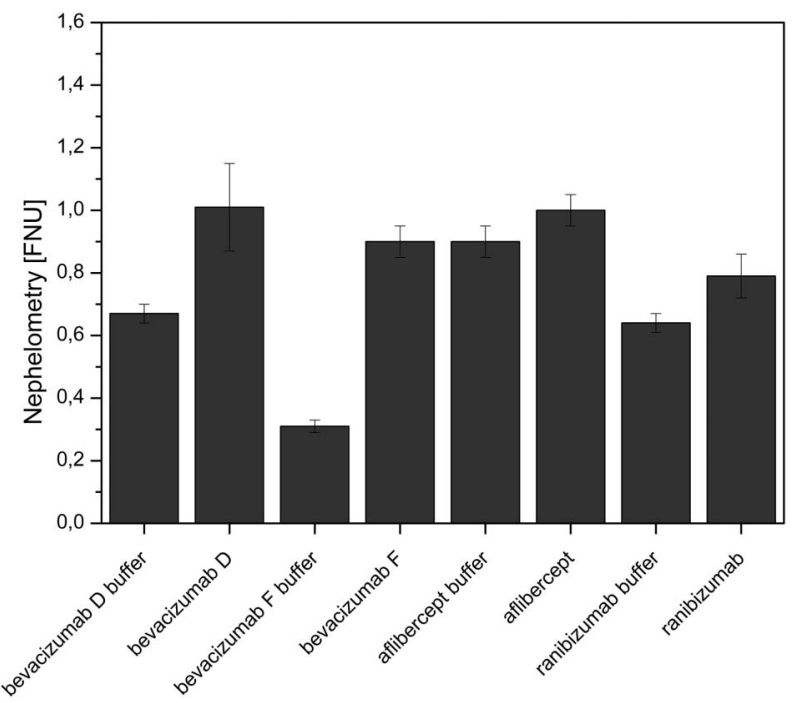

Fig. 1. Nephelometry data for buffers and diluted (1:20) protein solutions.

particles was set to $1.32 \mathrm{~g} / \mathrm{mL}$ and for silicone oil to $0.97 \mathrm{~g} / \mathrm{mL}$. The software ParticleLab V 1.9 (Affinity Biosensors LLC) was used for analysis. Each product was measured three times.

\section{Results}

\section{Nephelometry}

The determination of the opalescence of the buffer and protein solutions showed for all samples very low values (Figure 1). The addition of the protein solutions to the corresponding filtered placebo buffers led to a slight increase of the turbidity. One reason for the slightly lower opalescence value for the diluted ranibizumab samples in comparison with the other three products is the lower concentration of ranibizumab by a factor of 2.5 and four to bevacizumab and aflibercept, respectively. Overall, the samples were clear and no particles visible.

\section{Light Obscuration and Micro-Flow Imaging}

The particle burden in the subvisible range was measured with light obscuration and Micro-Flow Imaging (Table 1). The filtered placebo buffer solutions contained only a minor amount of particles $(<1,100$ particles $[\geq 1 \mu \mathrm{m}] / \mathrm{mL})$, whereas all protein solutions, except bevacizumab F, showed a (calculated) particle level in a range of around 36,000 to 42,000 particles $(\geq 1 \mu \mathrm{m}) / \mathrm{mL}$. Bevacizumab $\mathrm{F}$ displayed particle counts by a factor of at least four (light obscuration) and nine (Micro-Flow Imaging) higher than the other samples. Ranibizumab had the overall lowest particle count. The difference in the solutions with and without protein clearly demonstrated the presence of many small protein and silicone oil particles in the product solutions. Particles larger than $10 \mu \mathrm{m}$ as well as $25 \mu \mathrm{m}$ were on a low level, if existing at all.

\section{Nanotracking Analysis}

Measuring submicrometer particles with nanotracking analysis revealed a particle level of up to 102 million particles/mL for all placebo buffers (Figure 2). In comparison, highly purified water had a particle count of around 12 million particles $/ \mathrm{mL}$. In the protein samples, however, hundreds of millions of particles in the low nanometer range were detected. The highest value with 6,375 million particle $/ \mathrm{mL}$ was obtained for bevacizumab $\mathrm{F}$, followed by aflibercept with 4,082 million particles $/ \mathrm{mL}$. The high particle count observed for aflibercept can be attributed to the highest protein concentration. Bevacizumab D showed less than half the number and ranibizumab showed about one-fourth of the number of submicroparticles compared with aflibercept. The mean particle size for all drug samples

Table 1. The Total Particle Count (Particles $\geq 1 \mu \mathrm{m}$, Calculated After Measuring Samples With 1:20 Dilution) of Each Sample as Determined by Light Obscuration and Micro-Flow Imaging is Listed

\begin{tabular}{|c|c|c|c|c|c|c|}
\hline & \multicolumn{3}{|c|}{ Light Obscuration } & \multicolumn{3}{|c|}{ Micro-Flow Imaging } \\
\hline & \multicolumn{3}{|c|}{ Particles $/ \mathrm{mL} \geq$} & \multicolumn{3}{|c|}{ Particles $/ \mathrm{mL} \geq$} \\
\hline & $1 \mu \mathrm{m}$ & $10 \mu \mathrm{m}$ & $25 \mu \mathrm{m}$ & $1 \mu \mathrm{m}$ & $10 \mu \mathrm{m}$ & $25 \mu \mathrm{m}$ \\
\hline $\begin{array}{l}\text { Bevacizumab D buffer } \\
\text { Bevacizumab D } \\
\text { Bevacizumab F buffer } \\
\text { Bevacizumab F } \\
\text { Aflibercept buffer } \\
\text { Aflibercept } \\
\text { Ranibizumab buffer } \\
\text { Ranibizumab }\end{array}$ & $\begin{aligned} 546 & \pm 7 \\
41,733 & \pm 9,374 \\
81 & \pm 6 \\
182,919 & \pm 2,168 \\
1,049 & \pm 41 \\
36,096 & \pm 5,356 \\
1,093 & \pm 95 \\
37,755 & \pm 14,715\end{aligned}$ & $\begin{aligned} 13 & \pm 6 \\
622 & \pm 212 \\
3 & \pm 3 \\
2,126 & \pm 151 \\
6 & \pm 4 \\
163 & \pm 100 \\
5 & \pm 1 \\
570 & \pm 490\end{aligned}$ & $\begin{array}{c}7 \pm 5 \\
82 \pm 122 \\
0 \\
37 \pm 46 \\
1 \pm 1 \\
7 \pm 13 \\
0 \\
82 \pm 90\end{array}$ & $\begin{aligned} 54 & \pm 23 \\
42,848 & \pm 12,097 \\
498 & \pm 58 \\
414,308 & \pm 40,781 \\
255 & \pm 47 \\
44,299 & \pm 4,244 \\
121 & \pm 70 \\
19,815 & \pm 9,358\end{aligned}$ & $\begin{aligned} & 0 \\
535 & \pm 463 \\
7 & \pm 13 \\
2,663 & \pm 3,107 \\
0 & \\
271 & \pm 470 \\
0 & \\
267 & \pm 463\end{aligned}$ & $\begin{array}{l}0 \\
0 \\
0 \\
0 \\
0 \\
0 \\
0 \\
0\end{array}$ \\
\hline
\end{tabular}

\footnotetext{
The table further contains the particle numbers of interest regarding the USP requirements (particles $\geq 10 \mu \mathrm{m}$ and particles $\geq 25 \mu \mathrm{m}$ ).
} 


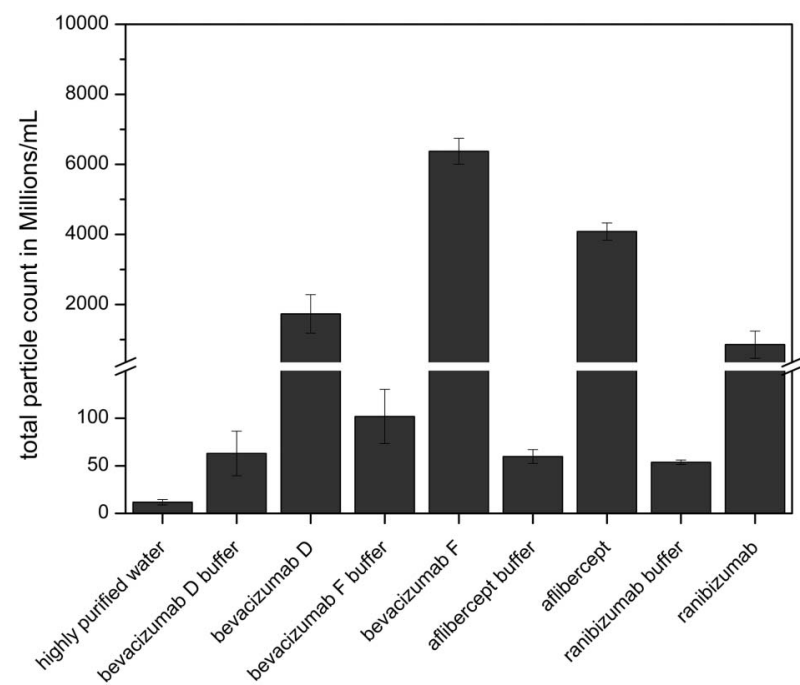

Fig. 2. The total (calculated) particle count $/ \mathrm{mL}$ of all nanometer particles is displayed for each sample as determined by nanotracking analysis.

was around $184 \mathrm{~nm} \pm 21 \mathrm{~nm}$. Aflibercept and ranibizumab nanoparticles had a similar mean particle diameter of $163 \mathrm{~nm} \pm 10 \mathrm{~nm}$ and $171 \mathrm{~nm} \pm 35 \mathrm{~nm}$, whereas bevacizumab $\mathrm{D}$ and bevacizumab $\mathrm{F}$ particles showed a broader distribution and a larger mean value of $192 \mathrm{~nm} \pm 62 \mathrm{~nm}$ and $209 \mathrm{~nm} \pm 11 \mathrm{~nm}$, respectively.

\section{Resonant Mass Measurement}

For the differentiation of silicone oil and protein particles, resonant mass measurement was performed (Figure 3). Overall, the particle burden of all solutions was very low and near the detection limit because of the high cleanliness of the samples. For comparison,

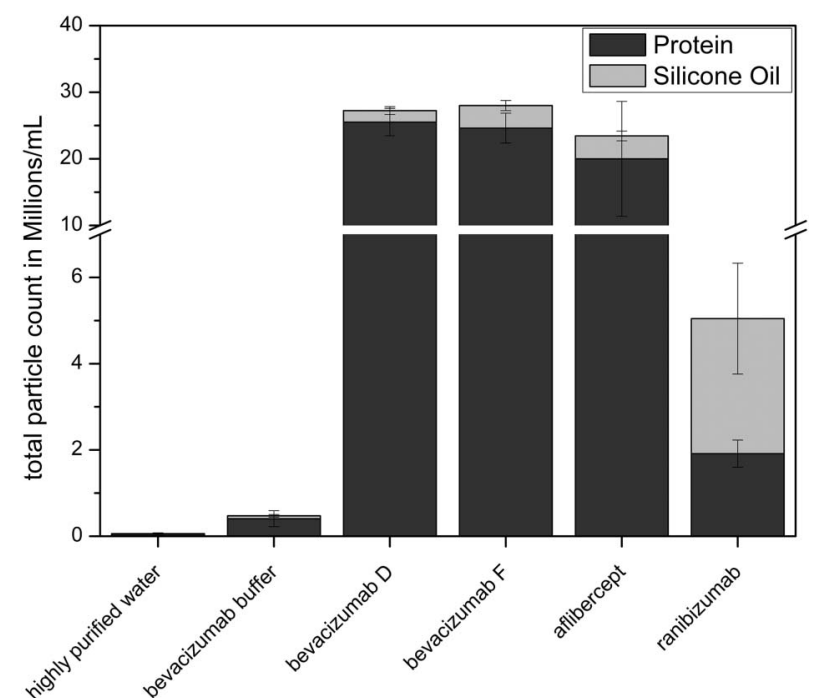

Fig. 3. The (calculated) cumulative particle count/mL of silicone oil and protein particles is shown as determined by resonant mass measurement. highly purified water had a particle burden of around 50,000 particles $(\geq 0.3 \mu \mathrm{m}) / \mathrm{mL}$ and a buffer showed values of 400,000 particles $(\geq 0.3 \mu \mathrm{m}) / \mathrm{mL}$. In all cases, silicone oil droplets were detected beside protein particles. The particle numbers were similar for bevacizumab $\mathrm{D}$, bevacizumab $\mathrm{F}$ and aflibercept; ranibizumab showed a much smaller overall particle number. For bevacizumab D, bevacizumab $F$ and aflibercept, a relatively small amount of silicone oil in comparison with the amount of protein particles was found. Silicone oil droplets are more dominant for ranibizumab, which is stored in a siliconized glass syringe and has an overall lower protein content.

\section{High-performance Size-exclusion Chromatography}

Bevacizumab D and F showed similar shares of soluble protein species as detected with HP-SEC (Figure 4). One peak represented the monomer, whereas the other ones represented dimers and higher molecular weight protein species. Tiny amounts of higher molecular weight protein species made a percentage of around $0.1 \%$, whereas the monomer accounted for around $98.2 \%$ and the dimers for roughly $1.7 \%$. Two peaks were found for aflibercept, representing the monomer and higher molecular species with a share of $98.8 \%$ and $1.2 \%$, respectively. For ranibizumab, only a monomer peak was detected.

\section{Discussion}

Intravitreal injection of anti-VEGF drugs can lead to an increased long-term IOP., ${ }^{4,5-20}$ Several mechanisms to explain this phenomenon including the possibility that protein aggregates and silicone oil microdroplets are responsible for the IOP elevation are discussed. ${ }^{22-24}$ Protein aggregates can be formed

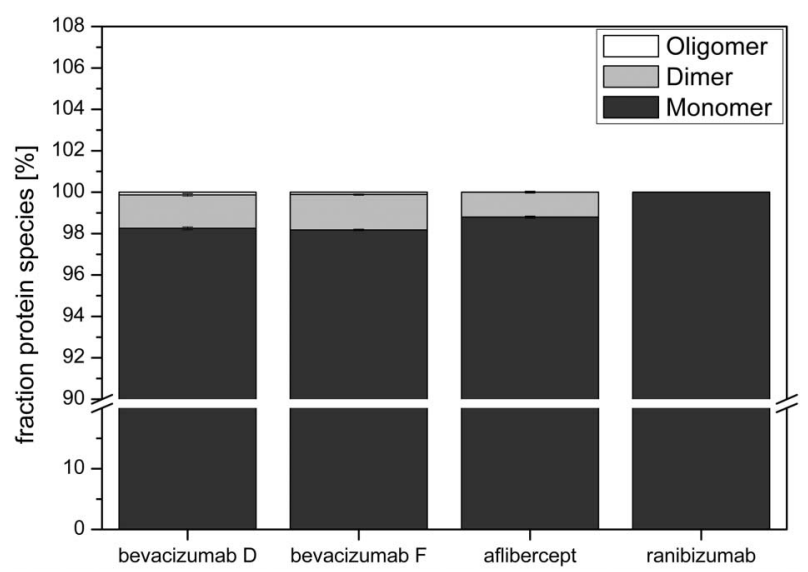

Fig. 4. Determination of the relative amount of protein species for different anti-VEGF drugs with HP-SEC. 
by various pathways, including temperature, light, freeze-thawing or shaking during drug transportation and handling or just by long-term storage..$^{25,29}$ The major source for silicone oil particles is the primary packaging container of the drug substance. Other sources could be silicone-oil-coated stoppers, the syringe used for drug aspiration or the needles used for withdrawing or injection of the drug.

Obstruction of the outflow pathway by particulate matter with IOP elevation is a well-known phenomenon in experimental glaucoma models. ${ }^{30}$

To the best knowledge of the authors, this is the first study directly comparing subvisible particle numbers and type in all three clinically used anti-VEGF drugs in the current application form.

In this study, the level and nature of the particles found in anti-VEGF drugs for intravitreal injection were identified and quantified.

The diluted samples showed no sign of visible particles before analysis, which was confirmed by low nephelometry data (Figure 1) and overall moderate-tolow particle counts for all products except bevacizumab F (Table 1). Eventually, the high particle count in bevacizumab $\mathrm{F}$ in comparison with the agents could be explained by the primary packaging material. For expelling the protein solution, an external $30 \mathrm{G}$ needle was attached to the syringe for all agents beside bevacizumab F. Bevacizumab F was supplied with a staked-in needle syringe. In another intravitreal injection study, intravitreal silicone oil droplets were more often detected with staked-in needle syringes than with luer cone syringes with an attached needle. The explanation of the authors was that a $50-\mu \mathrm{L}$ residual space is present in the needle hub for attached needles. For staked-in needles, this space is missing. In this space, silicone oil, which was scratched off the syringe barrel during ejection, can accumulate and is not injected into the eye, whereas it is in the staked-in needle syringe. ${ }^{31}$ This hypothesis is supported by observations during preparation of this study. The loss of volume was higher for bevacizumab $\mathrm{D}$; whereas in case of bevacizumab F, the complete small volume of $50 \mu \mathrm{L}$ could be expelled. Other factors playing a role in the higher particle count of bevacizumab F could be the product itself or handling during storage, repackaging, or transportation. For ranibizumab, one should keep in mind that it has a 2.5 , respectively, 4-fold lower protein concentration than the other products and the overall lower particle counts can in part be explained by that. Despite moderate-to-low particle counts in three out of four products, it is notable that all investigated products would theoretically not meet the specifications by U. S. Pharmacopeial Convention reference standard (USP) 789 (Table 1). ${ }^{32}$ USP 789 deals with the foreign particulate matter in ophthalmic solutions and requires a particle count below 50 particles $/ \mathrm{mL} \geq 10 \mu \mathrm{m}, 5$ particles $/ \mathrm{mL} \geq 25 \mu \mathrm{m}$ and 2 particles $/ \mathrm{mL} \geq 50 \mu \mathrm{m},{ }^{32}$ respectively. It has to be mentioned that our measurements were performed according to USP 787, not according to USP 788 (as it is normally required in USP 789). ${ }^{32-34}$ USP 787 differs from USP 788 mainly by the analyzed volume. USP 787 is designed for therapeutic protein injections with low volumes and can be performed with $0.2 \mathrm{~mL}$ to $0.5 \mathrm{~mL}$, whereas USP 788 would require a volume of $25 \mathrm{~mL}$. The particle number limits are the same for USP 787 and USP 788. ${ }^{33,34}$ The filtered aflibercept shows the best values regarding these requirements, although it would not meet them. Similar findings were already reported by Palmer et al and Yannuzzi et al..$^{35,36}$ They found in repackaged as well as in original bevacizumab particle counts higher than the limits set by the pharmacopoeia. ${ }^{36}$ A future solution to reduce particle numbers and to fulfill the requirements by the USP might be to filter the protein solutions before administration with a lower pore size filter (e.g., $0.2 \mu \mathrm{m}) .{ }^{37}$ Further, a batch-to-batch variation cannot be excluded because all our samples derived from one batch. Such a variation is possible as several other reports show. ${ }^{25,35,36,38}$ Particle levels do not only vary between different compounders but may even vary between syringes produced from the same original vial content. ${ }^{25,26,36}$ Analyzed samples from this study were taken from standard clinical settings and therefore reflect real live anti-VEGF samples for injections in patients.

So far, only Micro-Flow Imaging data are published to quantify silicone oil and protein particles in ophthalmic preparations. ${ }^{25} \mathrm{~A}$ drawback of this method is that a reliable differentiation is only possible at particle sizes over $5 \mu \mathrm{m}$. Because smaller particles might have an effect on the trabecular meshwork, resonant mass measurement was applied. With this technique, also the nanometer range can be analyzed. The analysis revealed millions of nanometer-ranged silicone oil and protein particles (Figure 3). But, overall the samples contain a low amount of silicone oil and the absolute amount is similar for all four products in the study. The total particle number measured with resonant mass measurement is clearly lower for ranibizumab. The contribution of silicone oil microdroplets to the overall particle level in repackaged bevacizumab samples has been shown several times. ${ }^{25,38}$ It was observed that the amount of silicone oil has not changed much over the investigated period of several weeks for nearly all tested samples. ${ }^{25,36,38}$ Nevertheless, the particle burden in repackaged bevacizumab increased over time, ${ }^{25,36}$ suggesting protein aggregation, beside silicone oil as cause for the 
particle elevation. ${ }^{36}$ Otherwise, bevacizumab seems to be stable for several weeks in repackaged syringes. ${ }^{25,36,38,39}$

Nanotracking analysis measurements revealed a high amount of nanosized particles (Figure 2) and confirmed the overall particle number trends gained by light obscuration and MFI (Table 1).

For the identification of the amount of soluble protein aggregates, HP-SEC was carried out (Figure 4). Overall, the data correlate well with the findings for the insoluble particles. In accordance with literature, bevacizumab contains a small percentage of higher molecular weight species. The investigated bevacizumab samples had an amount of roughly $1.8 \%$, whereas others detected a value of $1.56 \%{ }^{38}$ or even higher. ${ }^{25,40}$ Besides the monomer peak, a protein dimer peak was observed as well for aflibercept in a low concentration of $1.2 \%$ of the total protein concentration. The higher molecular species peak was so far not described in literature. ${ }^{41}$ The detection of only the ranibizumab monomer peak with HP-SEC was in accordance with literature. ${ }^{40}$

Several authors have postulated mechanisms explaining long-term IOP elevation after repeated anti-VEGF injections. $6,7,10,25$ Most mechanisms refer to mechanic or postinflammatory occlusion of the trabecular meshwork outflow pathway. None of these mechanisms have been proved so far, possibly reasons are multifactorial. Direct toxic effects have been examined as well; but even in much higher doses than clinically used, there is no toxic effect of anti-VEGF agents in laboratory setting. ${ }^{42}$

\section{Conclusion}

Summarizing, the product quality of the repackaged bevacizumab $\mathrm{D}$, the aflibercept vial, and the new siliconized glass syringe ranibizumab is overall similar. Repackaged bevacizumab $\mathrm{F}$ shows a much higher particulate burden, particularly when the standard method of light obscuration is applied. This might be due to the fact that a staked-in needle syringe was used in contrast to the other products, but also other reasons cannot be excluded. Ranibizumab displays in the majority of the applied analytical methods the highest quality with regard to protein-based submicron particles. However, one should keep in mind that protein concentration in ranibizumab is the lowest one. At least with the new syringe-packaged ranibizumab product, differences to aflibercept like they were hypothesized in the VIEW 1 and 2 study could no longer be correlated with high particle burden in future use. Further, it can be stated that repackaging in general does not lead to inferior quality regarding particulate levels compared with "original" products. But already with only two repackaged bevacizumab products in hand, relevant differences could be detected. With only one batch of repackaged bevacizumab $\mathrm{F}$ at disposal, it is impossible to judge the cause for its inferior performance in comparison with the other investigated samples. When it comes to larger, two digit micrometer-sized particles application of a filter (needle) like for aflibercept appears helpful, although such a filter does not reduce smaller particles.

In summary, it is important to make clear that none of the investigated three agents stood out in terms of particulate impurity. We found high numbers of submicron particles with different analytical methods. The relevance of such particles is still unclear, nor do we have specifications, or an industry standard for quantifying them. Therefore, caution has to be applied before drawing conclusions. Yet, in the context of the ophthalmic use of protein drug products and the clinical experience with elevated IOP, it appears urgent to put more effort into research correlating these factors.

Key words: aflibercept, bevacizumab, contamination, intraocular pressure, protein particles, ranibizumab, silicone oil.

\section{Acknowledgments}

The authors thank Coriolis Pharma Research GmbH, Martinsried, Germany, for providing access to the resonant mass measurement and nanotracking analysis system.

\section{References}

1. Berg K, Hadzalic E, Gjertsen I, et al. Ranibizumab or bevacizumab for neovascular age-related macular degeneration according to the Lucentis compared to Avastin study treat-and-extend protocol: two-year results. Ophthalmology 2016;123:51-59.

2. Brown DM, Kaiser PK, Michels M, et al. Ranibizumab versus verteporfin for neovascular age-related macular degeneration. N Engl J Med 2006;355:1432-1444.

3. Heier JS, Brown DM, Chong V, et al. Intravitreal aflibercept (VEGF trap-eye) in wet age-related macular degeneration. Ophthalmology 2012;119:2537-2548.

4. Kiddee W, Montriwet M. Intraocular pressure changes in nonglaucomatous patients receiving intravitreal anti-vascular endothelial growth factor agents. PLoS One 2015;10:e0137833.

5. Farhood QK, Twfeeq SM. Short-term intraocular pressure changes after intravitreal injection of bevacizumab in diabetic retinopathy patients. Clin Ophthalmol 2014;8:599-604.

6. Bakri SJ, McCannel CA, Edwards AO, Moshfeghi DM. Persisent ocular hypertension following intravitreal ranibizumab. Graefes Arch Clin Exp Ophthalmol 2008;246:955-958.

7. Kahook MY, Kimura AE, Wong LJ, et al. Sustained elevation in intraocular pressure associated with intravitreal bevacizumab 
injections. Ophthalmic Surg Lasers Imaging 2009;40: 293-295.

8. Abedi G, Adelman RA, Salim S. Incidence and management of elevated intraocular pressure with antivascular endothelial growth factor agents. Semin Ophthalmol 2013;28:126-130.

9. Adelman RA, Zheng Q, Mayer HR. Persistent ocular hypertension following intravitreal bevacizumab and ranibizumab injections. J Ocul Pharmacol Ther 2010;26:105-110.

10. Good TJ, Kimura AE, Mandava N, Kahook MY. Sustained elevation of intraocular pressure after intravitreal injections of anti-VEGF agents. Br J Ophthalmol 2011;95:1111-1114.

11. Hoang QV, Mendonca LS, Della Torre KE, et al. Effect on intraocular pressure in patients receiving unilateral intravitreal anti-vascular endothelial growth factor injections. Ophthalmology 2012;119:321-326.

12. Hoang QV, Tsuang AJ, Gelman R, et al. Clinical predictors of sustained intraocular pressure elevation due to intravitreal antivascular endothelial growth factor therapy. Retina 2013;33: 179-187.

13. Wehrli SJ, Tawse K, Levin MH, et al. A lack of delayed intraocular pressure elevation in patients treated with intravitreal injection of bevacizumab and ranibizumab. Retina 2012; 32:1295-1301.

14. Sniegowski M, Mandava N, Kahook MY. Sustained intraocular pressure elevation after intravitreal injection of bevacizu$\mathrm{mab}$ and ranibizumab associated with trabeculitis. Open Ophthalmol J 2010;4:28-29.

15. Matsubara H, Miyata R, Kobayashi M, et al. A case of sustained intraocular pressure elevation after multiple intravitreal injection of ranibizumab and aflibercept for neovascular age-related macular degeneration. Case Rep Ophthalmol 2016;7:230-236.

16. Mathalone N, Arodi-Golan A, Sar S, et al. Sustained elevation of intraocular pressure after intravitreal injections of bevacizu$\mathrm{mab}$ in eyes with neovascular age-related macular degeneration. Graefes Arch Clin Exp Ophthalmol 2012;250:1435-1440.

17. Dedania VS, Bakri SJ. SUSTAINED elevation of intraocular pressure after intravitreal anti-VEGF agents: what is the evidence? Retina 2015;35:841-858.

18. Bressler SB, Almukhtar T, Bhorade A, et al. Repeated intravitreous ranibizumab injections for diabetic macular edema and the risk of sustained elevation of intraocular pressure or the need for ocular hypotensive treatment. JAMA Ophthalmol 2015;133:589-597.

19. Baek SU, Park IW, Suh W. Long-term intraocular pressure changes after intravitreal injection of bevacizumab. Cutan Ocul Toxicol 2016;35:310-314.

20. Rusu IM, Deobhakta A, Yoon D, et al. Intraocular pressure in patients with neovascular age-related macular degeneration switched to aflibercept injection after previous anti-vascular endothelial growth factor treatments. Retina 2014;34:2161-2166.

21. Freund KB, Hoang QV, Saroj N, Thompson D. Intraocular pressure in patients with neovascular age-related macular degeneration receiving intravitreal aflibercept or ranibizumab. Ophthalmology 2015;122:1802-1810.

22. Bakri SJ, Moshfeghi DM, Francom S, et al. Intraocular pressure in eyes receiving monthly ranibizumab in 2 pivotal agerelated macular degeneration clinical trials. Ophthalmology 2014;121:1102-1108.

23. Ricca AM, Morshedi RG, Wirostko BM. High intraocular pressure following anti-vascular endothelial growth factor therapy: proposed pathophysiology due to altered nitric oxide metabolism. J Ocul Pharmacol Ther 2015;31:2-10.
24. Bakri SJ, Ekdawi NS. Intravitreal silicone oil droplets after intravitreal drug injections. Retina 2008;28:996-1001.

25. Liu L, Ammar DA, Ross LA, et al. Silicone oil microdroplets and protein aggregates in repackaged bevacizumab and ranibizumab: effects of long-term storage and product mishandling. Invest Ophthalmol Vis Sci 2011;52:1023-1034.

26. Kahook MY, Liu L, Ruzycki P, et al. High-molecular-weight aggregates in repackaged bevacizumab. Retina 2010;30:887892.

27. FDA approves Lucentis (ranibizumab injection) prefilled syringe. https://www.gene.com/media/press-releases/14640/ 2016-10-14/fda-approves-genentechs-lucentis-ranibiz. October 14, 2016. Accessed March 2, 2016.

28. Michaud J-E, Sigg J, Boado L, et al. Ranibizumab pre-filled syringe approved in the European Union: innovation to improve dose accuracy, reduce potential infection risk, and offer more efficient treatment administration. Invest Ophthalmol Vis Sci 2014;55:1949.

29. Mahler HC, Friess W, Grauschopf U, Kiese S. Protein aggregation: pathways, induction factors and analysis. J Pharm Sci 2009;98:2909-2934.

30. Weber AJ, Zelenak D. Experimental glaucoma in the primate induced by latex microspheres. J Neurosci Methods 2001;111: 39-48.

31. Scott IU, Oden NL, VanVeldhuisen PC, et al. SCORE Study Report 7: incidence of intravitreal silicone oil droplets associated with staked-on vs luer cone syringe design. Am J Ophthalmol 2009;148:725-732.e727.

32. The United States Pharmacopeial Convention. General Chapter $<789>$ Particulate Matter in Ophthalmic Solutions. Rockville, MD: United States Pharmacopeia; 2016.

33. The United States Pharmacopeial Convention. General Chapter $<788>$ Particulate Matter in Ophthalmic Solutions. Rockville, MD: United States Pharmacopeia; 2016.

34. The United States Pharmacopeial Convention. General Chapter $<787>$ Particulate Matter in Ophthalmic Solutions. Rockville, MD: United States Pharmacopeia; 2016.

35. Yannuzzi NA, Klufas MA, Quach L, et al. Evaluation of compounded bevacizumab prepared for intravitreal injection. JAMA Ophthalmol 2015;133:32-39.

36. Palmer JM, Amoaku WM, Kamali F. Quality of bevacizumab compounded for intravitreal administration. Eye 2013;27: 1090-1097.

37. Montero JA, Ruiz-Moreno JM, Sanchis-Merino E. Intravitreal ranibizumab, with or without filter? Acta Ophthalmol 2012;90: e405-e406.

38. Paul M, Vieillard V, Roumi E, et al. Long-term stability of bevacizumab repackaged in $1 \mathrm{~mL}$ polypropylene syringes for intravitreal administration. Ann Pharm Fr 2012;70:139-154.

39. Khalili H, Sharma G, Froome A, et al. Storage stability of bevacizumab in polycarbonate and polypropylene syringes. Eye 2015;29:820-827.

40. Veurink M, Stella C, Tabatabay C, et al. Association of ranibizumab (Lucentis $(\mathrm{R})$ ) or bevacizumab (Avastin(R)) with dexamethasone and triamcinolone acetonide: an in vitro stability assessment. Eur J Pharm Biopharm 2011;78:271-277.

41. Moreno MR, Tabitha TS, Nirmal J, et al. Study of stability and biophysical characterization of ranibizumab and aflibercept. Eur J Pharm Biopharm 2016;108:156-167.

42. Kahook MY, Ammar DA. In vitro effects of antivascular endothelial growth factors on cultured human trabecular meshwork cells. J Glaucoma 2010;19:437-441. 